\title{
Laparoscopic Repair of Pediatric Inguinal Hernia by Disconnection of the Hernial Sac
}

\author{
MOSTAFA M. EL-SAYED, M.Sc.; MOHAMMAD G. KHAIR- ALLAH, M.D.; \\ AKRAM M. ELBATARNY, M.D. and AMEL A. HASHISH, M.D.
}

The Department of Pediatric Surgery, Faculty of Medicine, Tanta University

\begin{abstract}
Background: Several techniques are used for laparoscopic treatment of pediatric inguinal hernia (PIH). Disconnection and peritoneal closure was described by Becmeur in 2004, as an effective technique mimicing open technique. Others described disconnection only as an effective laparoscopic treatment of PIH specially for small defects. Here in, we describe the short term results of laparoscopic disconnection only of the hernial sac.

Patients and Methods: This prospective clinical study was carried out in the Pediatric Surgery Unit, Tanta University Hospital, during the period from March 2016 to March 2017, on 15 patients with 20 pediatric inguinal hernias. All the cases were subjected to laparoscopic disconnection of the hernia sac without closure of peritoneum over internal ring.

Results: The operative data as well as postoperative course and complications specially recurrence were reported. Twenty hernias were repaired laparoscopically by disconnection of sac only. Operative time ranged from 30 to 42 minutes for unilateral cases while in bilateral cases, it ranged from 35 to 50 minutes. All cases were repaired laparoscopically with no conversion. Three recurrences occurred, all with ring diameter more than $10 \mathrm{~mm}$.

Conclusion: With enough experience LIHR is safe, feasible, and has no major complications and a small incidence of minor complications. With experienced hands $\mathrm{U} / \mathrm{S}$ is a good tool for examining the contralateral side in unilateral PIH and for detection of a CPPV (a latent hernia). sac disconnection is an effective laparoscopic treatment of PIH. However, it is associated with an unacceptable recurrence rate $(15 \%)$ in hernias $>10 \mathrm{~mm}$ in diameter. However, IRD is not the only factor contributing to recurrence.
\end{abstract}

Key Words: Laparoscopic - Hernia - Repair - Disconnection - Sac.

\section{Introduction}

PEDIATRIC inguinal hernia (PIH) is a common surgical problem, it represents about $15 \%$ of pediatric surgical practice [1]. Conventional Open repair

Correspondence to: Dr. Mostafa M. El-Sayed, The Department of Pediatric Surgery, Faculty of Medicine, Tanta University of inguinal hernia has been accepted as the gold standard treatment of PIH due to its lower morbidity, good cosmesis, and lower rates of recurrence [2]. However over the last 2 decades with advances in pediatric minimal invasive surgery (MIS), laparoscopy has become more popular for the management of PIH [3,4]. It offers many advantages over the open technique; magnification, detection of contralateral patent processus vaginalis (CPPV) and other various forms of hernias, and minimal manipulation of vas and vessels [5]. Several techniques have been described that involve the use of extra or intracorporeal knotting and high ligation with or without disconnection of peritoneum at the internal ring [6]. Laparoscopic disconnection of the hernial sac with closure of the peritoneum over the internal ring was described to mimic the open technique to decrease the incidence of recurrence $[7,8]$. Some authors reported that disconnection of the hernial sac without peritoneal closure is an effective treatment specially in small ring $10-20 \mathrm{~mm}$ $[9,10,11]$. The aim of this study was to evaluate the short term results of laparoscopic disconnection of the hernia sac in children, as regards operative details, feasibility, recurrence rate and postoperative complications.

\section{Patients and Methods}

This case series was carried out at Pediatric Surgical Unit, Tanta University Hospital, during the period from March 2016 to March 2017, on 15

\footnotetext{
Abbreviations:

IRD : Internal ring diameter.

PIH : Pediatric inguinal hernia Totally Extraperitoneal.

CPPV : Contralateral patent processus vaginalis.

PPV : Patent processus vaginalis.

MIS : Pediatric minimal invasive surgery.

LIHR : Laparoscopic inguinal hernia repair

PO : Postoperative.
} 
patients with 20 pediatric inguinal hernias. The study was approved by ethical committee of the faculty of medicine, Tanta university (Approval Code 30836/03/16). A written informed consent was taken. The procedure was explained in details and in a clear simple language. All possible complications were explained. We included 15 patients with 20 hernias who were subjected to laparoscopic disconnection of the hernia sac without closure of peritoneum over internal ring. The study included infants and children with primary uncomplicated PIH with an age ranged from one month to 2 years. The exclusion criteria included complicated pediatric Inguinal Hernia, cases of recurrent pediatric Inguinal Hernia, patients with undescended testis, patients with hydrocele, patients with chronic comorbidity as congenital heart disease and severe chest troubles and Patients with chronic cough or chronic constipation. All patients were subjected to full clinical evaluation and laboratory investigations as needed. Scrotal U/S was done to evaluate the internal ring diameter (IRD) and the contralateral side.

\section{Operative techniques:}

All patients received general anesthesia with endotracheal intubation in a supine position. The surgeon stood at the head of the table and patient, with the anesthesia machine moved to the right side of the operating table, the camera man to the left side of the surgeon, the scrub nurse to the left of the table and the monitor at the feet of the patient.

In all patients, an open technique was used to establish pneumoperitoneum at the site of umbilical port. The abdomen was insufflated with $\mathrm{CO} 2$, initially at $6-8 \mathrm{mmHg}$ pressure, with a flow of 1.5 $\mathrm{L} / \mathrm{min}$. Pressure was then raised to $8-12 \mathrm{mmHg}$ and flow to $2-3 \mathrm{~L} / \mathrm{min}$ depending on age. In addition to the umbilical port for the camera $(5 \mathrm{~mm}) 30^{\circ}$, two $(3$ or $5 \mathrm{~mm})$ trocars were inserted at the lateral margin of the right and left rectus sheath, about the level of the umbilicus under vision. The head of the table was lowered in Trendelenburg's position. Laparoscopy was used firstly to inspect peritoneal cavity and examine the hernial side and contralateral side as well. Size of the internal ring was measured with a thread stretched in a transverse manner between two laparoscopic graspers (Fig. 2).

The dissection was carried out by separating the hernia sac from the vascular structures and the vas, if male. Great care was taken when disconnection of hernial sac was done by using cautery and scissors (Fig. 3). Complete disconnection of the hernial sac for $360^{\circ}$ degrees is ensured, at least a circular area of $1 \mathrm{~cm}$ of deperitonealized surface around the internal ring was left (Fig. 4).

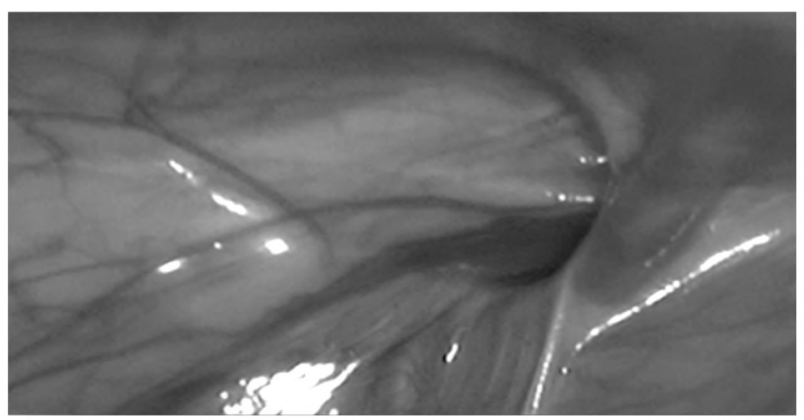

Fig. (1): PPV on the left side.

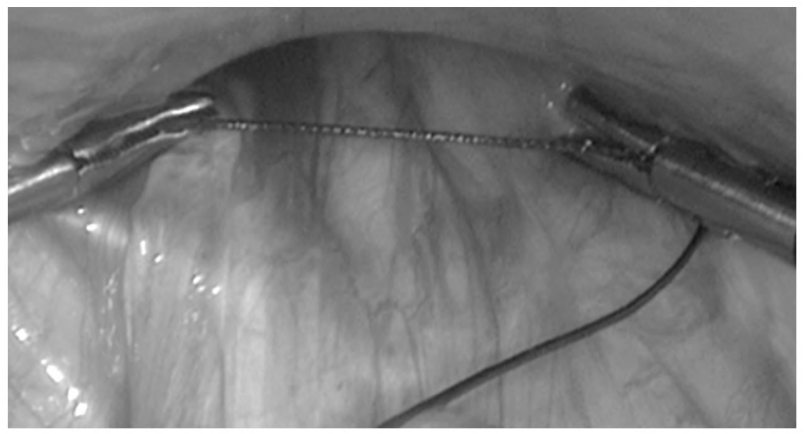

Fig. (2): Measuring the size of the internal ring.

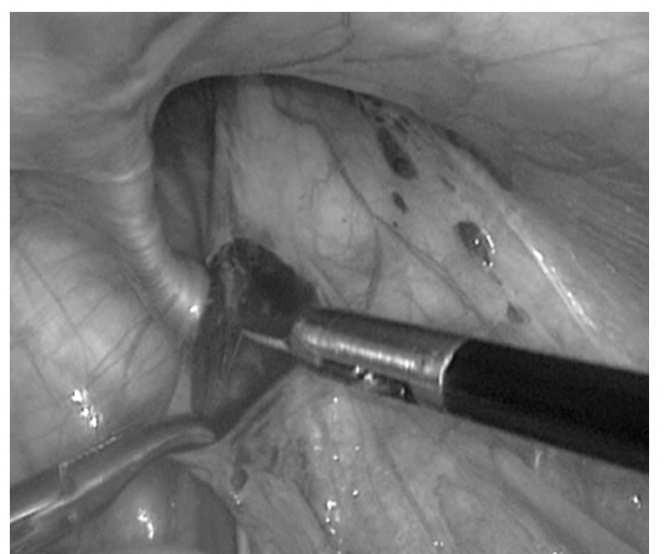

Fig. (3): Hernia sac separated from the vascular structures, and the vas, if male.

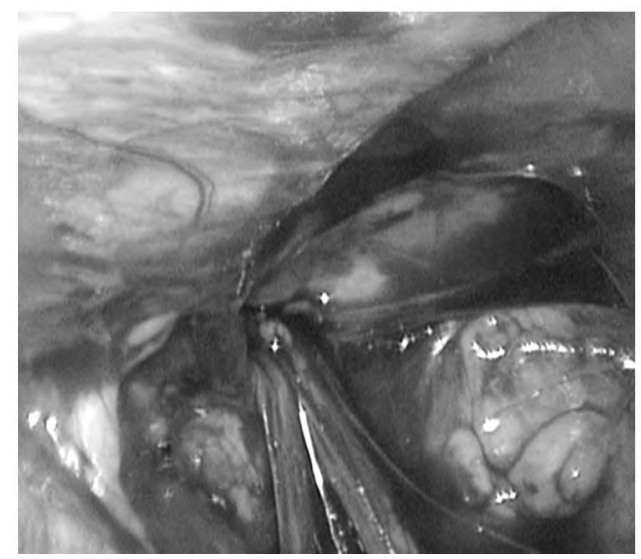

Fig. (4): The sac is completely removed with a circular area of parietal peritoneum. 


\section{Statistical analysis:}

Data were fed to the computer and analyzed using IBM SPSS software package version 20.0. (Armonk, NY: IBM Corp). Qualitative data were described using number and percent. Quantitative data were described using range (minimum and maximum), mean, standard deviation and median. Significance of the obtained results was judged at the 5\% level. Chisquare $\left(\chi^{2}\right)$ and Fisher's exact test were used for comparing between the 2 groups, for example, demographic data, clinical data, recurrence, scrotal edema. Mann-Whitney test was used to for comparing between the 2 groups for, operating Time, hospital stay and IR diameter.

\section{Results}

This study included 15 patients who presented with unilateral primary uncomplicated PIH. Their ages ranged from 1 month to 23 months (mean: 6.43 months). Our study included 12 males and 3 females. Thirteen cases $(86.7 \%)$ cases were Rt. sided clinical hernia with 5 case associated with a contralateral hernia proved by preoperative U/S and on laparoscopic examination, while $2(13.3 \%)$ cases were Lt. sided clinical hernia. The (IRD) by preoperative U/S ranged from $5 \mathrm{~mm}$ to $15 \mathrm{~mm}$ ) mean: $8.38 \mathrm{~mm}$ ) and by laparoscopy, it ranged from $6 \mathrm{~mm}$ to $22 \mathrm{~mm}$ (mean: $11.95 \mathrm{~mm}$ ). In this study, 20 hernias were repaired laparoscopically. All cases were done laparoscopically without conversion to open technique. Operative time was calculated from skin incision to skin closure. It ranged from 30 to 42 minutes (mean time is $34.6 \pm$ SD 3.71) in unilateral cases and from 35 to 50 minutes (mean time is $39.4 \pm \mathrm{SD} 4.39$ ) in bilateral cases. No intraoperative complications; bleeding, injury of the vas or vessels or missed needles were encountered.

Table (1): Preoperative data.

\begin{tabular}{ll}
\hline & No. of patients \\
\hline Sex: & 12 \\
Male & 3 \\
Female & \\
Age: & $1.0-23$ \\
$\quad$ Range & $6.43 \pm 5.73$ \\
$\quad$ Mean \pm SD & \\
U/S diameter of IR $(\mathrm{mm}):$ & $5.0-15.0$ \\
$\quad$ Range & $3.04 \pm 8.38$ \\
$\quad$ Mean \pm SD & \\
Clinical hernia: & 13 \\
Rt. Side & 2 \\
Lt. Side & \\
US. detected hernia: & 0 \\
Rt. Side & 5 \\
Lt. Side &
\end{tabular}

Table (2): Operative data.

\begin{tabular}{ll}
\hline & No. of hernias $=20$ \\
\hline Operative time (min.): & \\
Unilateral cases: & \\
$\quad$ Range & $35-50$ \\
$\quad$ Mean \pm SD & $34.6 \pm 3.71$ \\
Bilateral cases: & \\
$\quad$ Range & $38.0-53.0$ \\
Mean \pm SD & $45.1 \pm 4.87$ \\
IRD (mm) Intra-operative: & \\
Range & $6-22$ \\
Mean \pm SD & $11.95 \pm 2.56$ \\
\hline
\end{tabular}

$\mathrm{IRD}=$ Internal ring diameter.

\section{Postoperative course: Table (3)}

Oral fluids were tolerated at average of 2-3 hours after procedure. All patients received I.V paracetamol $(15 \mathrm{mg} / \mathrm{kg} / \mathrm{dose})$. Recurrence occurred in 3 cases $(15 \%)$. Recurrence occurred in all cases on the right side and with internal ring diameter more than $10 \mathrm{~mm}$. Recurrence occurred during the first 24 hours after the operation in 2 cases while it appeared one week after the operation in 1 case. Two of them with early recurrence were repaired laparoscopically the next day with peritoneal closure. The case presenting after 1 week was repaired by open surgery. Transient scrotal edema developed in 3 cases $(15 \%)$. It resolved by conservative treatment after 2-4 days. No port site hernia and no wound infection developed in any case.

All patients were discharged the morning of the next day of operation except in the two cases $(5 \%)$ where recurrence occurred who were discharged on day 4 PO after repair of hernia. The 3 rd recurrent case was readmitted on detection of recurrence at the 1 st follow-up visit at outpatient clinic on day 7 PO. The mean hospital stay of all cases including the readmission hospital stay was 33.6 hours. The mean follow-up of the cases in this study was 6 months as it ranged from 3 to 11 months.

Table (3): Postoperative data.

\begin{tabular}{lcc}
\hline & \multicolumn{2}{c}{$\begin{array}{c}\text { Group A } \\
\text { No. of hernias }=20\end{array}$} \\
\cline { 2 - 3 } & No. $\%$ \\
\hline Scrotal edema & 3 & 15 \\
Recurrence & 3 & 15 \\
Time of hospital discharge: & & \\
$\quad$ 2nd PO day & 12 & 80.0 \\
4th PO day & 3 & 20.0 \\
Hospital stay (hours): & \multicolumn{2}{c}{33.6} \\
$\quad$ Mean & \multicolumn{2}{c}{} \\
\hline
\end{tabular}




\section{Discussion}

Inguinal hernia repair remains the most common operation performed by pediatric surgeons. It occurs in $0.8 \%$ to $4.4 \%$ of all children with higher incidence (up to $30 \%$ ) in premature babies.(12) Conventional herniotomy is considered the gold standard treatment method for PIH [13]. In the last 2 decades, the advances of minimally invasive surgery has completely changed the management of pediatric inguinal hernias [14,15]. With feasibility and safety of laparoscopy firmly established in pediatric surgical practice, $[\mathbf{1 6 , 1 7 ]}$ there is a justified trend towards the use of minimal invasive surgery to manage of PIH because of the advantages it offers over the conventional procedure [3,4]. Many technical variations have been described for laparoscopic repair of PIH and can be categorized as either intracorporeal or extracorporeal/percutaneous approaches [15]. Early reports described high ligation of intact peritoneum at the internal ring using purse string, $Z$ suture or a flip-flap technique. However, they were associated with high recurrence rate especially when skip area was left in males over the vas and vessels $[\mathbf{1 4 , 1 8 , 1 9 ]}$. For that reason, techniques which transect the peritoneum over the internal ring were introduced to make some trauma $\&$ scarring at the hernia orifice to help more durable healing $[\mathbf{2 0 , 2 1 ]}$. The recurrence rate dropped from $3.7 \%$ in intact peritoneum closure to $0 \%$ in series transecting the peritoneum $[\mathbf{7 , 8 , 2 1 , 2 2 ]}$. Involving some component of trauma to the peritoneum is essential for durability of inguinal hernia repair. This certainly occurs during the open repair, where the sac is transected after ligation. In fact, it has been reported that the actual sac ligation may not be needed during repair, rather, just the sac transection $[\mathbf{9 , 2 3}]$

Our study was a prospective study that included 15 patients complaining of PIH collectively with 20 hernias. All cases were subjected to disconnection of the hernia sac without closure of peritoneum over internal ring. In this study, the age ranged from one month to 23 months. We excluded cases less that 1 month of age to avoid physiological insult of laparoscopic surgery in neonates, and the possibility of the need for an NICU admission that may not be available $[\mathbf{2 4 , 2 5}$. We also excluded cases older than 24 months to avoid a wide variation in the IR diameter that may be bigger with older ages and that may affect the outcome. Pant, et al., in 2014, included patients whose ages ranged from 12 to 144 months (mean 63.15 months) during his work [11]. They excluded infants from there study to avoid the possible criticism of leaving the peritoneum unsutured, may invite more recurrences in infants due to a suboptimal sealing mechanism of the conjoint muscle. Esposito et al., in 2010, included patients with PIH whose ages ranged from 1 to 12 months with median 6 or 7 months [20]. In this study, the male to female ratio was 4:1. Other reports described male to female ratio as $6.5: 1$ and 7.7:1 [11,26,27]. Riquelme et al., in 2010, reported laparoscopic hernia repair of 91 cases by disconnection only technique, however he added a purse string suture for case with IRD $>10 \mathrm{~mm}$. In their study, the recurrence rate was $0 \%$ after 4 years of follow-up [9]. García-Hernández et al., in 2012, described a technique for repair of PIH consisting of resection of the hernial sac without suture regardless of the sac's size, the recurrence rate was $0.53 \%$ [28]. Pant, et al., in 2014, reported repair of 38 hernia laparoscopically by disconnection only technique with recurrence rate 5.3\% [11]

In our study, $86.7 \%$ showed Rt. sided clinical hernia while $13.3 \%$ presented with Lt. sided clinical hernia. No cases presented with clinical bilateral hernia. Pant, et al., in 2014, reported that $63.3 \%$ showed Rt. sided clinical hernia while $31.7 \%$ presented with Lt. sided clinical hernia, and 5\% presented with bilateral clinical hernia [11]. Ibrahim in 2015 , reported $61.1 \%$ presented with Rt. sided clinical hernia while $16.7 \%$ presented with Lt. sided clinical hernia, and $22.2 \%$ presented with bilateral clinical hernia [29].

The operative time in the current study was calculated from skin incision to skin closure. It ranged from 30 to 42 (mean time was $34.6 \mathrm{~min} \pm$ SD 3.71) in unilateral cases and from 38.53 to $50 \mathrm{~min}$ (mean time was $39.4 \mathrm{~min} \pm \mathrm{SD} 4.39$ ) in bilateral cases. Riquelme et al., in 2010, reported that the operative time for resection of hernial sac ranged from 35 to $72 \mathrm{~min}$ (mean 40min). It was longer in the initial cases and shorter as experience was obtained [9]. The authors did not mention if that the time was for side of repair (unilateral or bilateral) or type of technique (disconnection only or disconnection with suture). Pant, et al., in 2014, reported that operative time was recorded from skin incision to closure of ports sites. In the disconnection group, most unilateral hernias were performed within $30 \mathrm{~min}$. almost all bilateral hernias were performed within 50min. [11]

In the current study, no major intraoperative complications. Similar results were also reported in many other studies were reported $[\mathbf{7 , 1 1 , 2 9 ]}$. A major criticism of the laparoscopic repair remains its recurrence rate. However, many studies reported that laparoscopic herniotomy or other techniques have no or minimal recurrences ranging from 0 to 
$3 \%[\mathbf{7 , 8 , 3 0 - 3 2}]$. Generally, the recurrence rate in Laparoscopic inguinal hernia repair (LIHR) could possibly be due to tension at the closure of the IIR, broken purse string suture, large hernia, missed special types of hernia and presence of skip area of sac especially over the vas and spermatic vessels without complete encirclement of the internal inguinal ring (IIR) [33]. In our study, recurrence occurred in 3 cases out of 20 hernias $(15 \%)$, all were on the RT. side with ring diameter $>10 \mathrm{~mm}$. Pant, et al., in 2014, reported that recurrence occurred in 2 of 38 hernias (5.3\%) in the disconnection group similar to what occurred in our study. Recurrence occurred with ring diameter $>10 \mathrm{~mm}$. [11].

García-Hernández et al., in 2012, also reported that recurrence occurred in 2 cases $(0.53 \%)$ [28] Riquelme et al., in 2010, did not report any recurrence over a period of 4 years of follow-up. He demonstrated that resection of sac alone is sufficient treatment of inguinal hernia in children but he recommended a purse string closure of rings $>10 \mathrm{~mm}[9]$. In the current study, recurrence occurred during the first 24 hours after the operation in 2 cases while it appeared one week after the operation in 1 case. Two of them were repaired laparoscopically with peritoneal closure but one was repaired by open procedure after failure a trial of laparoscopic repair. Pant, et al., in 2014, reported early recurrence in 2 of their cases (24-72 hours), and repair was done early by the open technique [11] García-Hernández et al., in 2012, reported that recurrence occurred in the 1st week after surgery. They reported that repair was done between 4 and 8 weeks after the surgery using conventional approach and recurrence was related to a defect in the technique because reoperation revealed incomplete sac resection in each case [28]. In the current study, repair was possible in the early postoperative period with differentiation of structures but failed in late cases where peritonealization of the surfaces previously denuded by sac disconnection accured with fibrosis, friability, also the vas and vessels were indistinguishable. So dissection was judjed as risky and conversion was safer. The percentage of recurrence in in this study is unacceptable (15\%). It is considered very high in comparison to other studies of laparoscopic hernia repair in children. Since all recurrence occurred in defects larger than $10 \mathrm{~mm}$, the disconnection only technique can be used in hernias $10 \mathrm{~mm}$ in diameter or less.

This is supported by Riquelme's and pant's series that advocate herniorrhaphy procedure rather than herniotomy in defects larger than $10 \mathrm{~mm}[\mathbf{9 , 1 1}]$ However, García-Hernández et al., performed re- section of the hernia sac without sutures regardless of the sac's size [28]. We also had 8 cases (40\%) with IR diameter of more than $10 \mathrm{~mm}$ which were repaired by sac disconnection only and yet no recurrence occurred. So further studies are required to determine the relation between IR diameter and recurrence in hernias repaired by disconnection only.

\section{Conflicts of interest:}

No conflict of interest has been declared.

\section{Authors' contributions:}

All authors had equal role in design, work, statistical analysis and manuscript writing.

\section{References}

1- YEUNG C. and LEE K.: Inguinal herniotomy: Laparoscopic assisted extra peritoneal technique. In: Bax K.N.A., Georgeson K.E., Rothenberg S.S., Valla J.S., Yeung C.K. (eds) Endoscopic Surgery in Infants and Children. Berlin Heidelberg, Springer, pp. 577-584, 2008.

2- SARANGA BHARATHI R., ARORA M. and BASKARAN V.: Minimal access surgery of pediatric inguinal hernias: A review. Surg. Endosc., 22: 1751-1762, 2008.

3- EL-GOHARY M.: Laparoscopic ligation of inguinal hernia in girls. Pediatr. Endosurg. Innov. Techn., 1: 185-187, 1997.

4- NG W.: Minimally invasive herniorrhaphy or laparoscopic inguinal high ligation. Surg. Endosc., 20: 1926-1927, 2009 .

5- MILTENBURG D., NUCHTERN J., BRANDT M., et al.: Laparoscopic evaluation of the pediatric inguinal hernia: a meta-analysis. J. Pediatr. Surg., 33 (6): 478-879, 1998

6- BHARATHI R., DABAS A., ARORA M., et al.: Laparoscopic ligation of internal ring-three ports versus singleport technique: Are working ports necessary? J. Laparoendosc Adv. Surg. Tech. A, 18: 891-4, 2008.

7- PONSKY T., NALUGO M., OSTLIE D., et al.: Pediatric Laparoscopic Inguinal Hernia Repair: A Review of the Current Evidence. Journal Of Laparoendoscopic \& Advanced Surgical Techniques, Volume 24: p 183-187, 2014.

8- BECMEUR F., PHILIPPE P., SCHULTZ A., et al.: A continuous series of 96 laparoscopic inguinal hernia repairs in children by a new technique. Surg. Endosc., 18: 1738-1741, 2004.

9- RIQUELME M., ARANDA A. and RIQUELME Q.M.: Laparoscopic Pediatric Inguinal Hernia Repair: No Ligation, Just Resection. Journal of Laparoendoscopic \& Advanced Surgical Techniques, Volume 20: 77- 80, 2010.

10- SHEHATA S., EL-ATTAR A., ATTIA M., et al.: Laparoscopic herniotomy in children: Prospective assessment of tertiary center experience in a developing country Hernia. Springer-Verlag France, 17: 229-234, 2013.

11- PANT N, AGGARWAL S. and RATAN S.: Laparoscopic repair of hernia in children: Comparison between ligation and nonligation of sac. J. Indian Assoc. Pediatr. Surg., 19: 76-9, 2014 
12- KUMAR A. and RAMAKRISHNAN T.: Single port laparoscopic repair of paediatric inguinal hernias: Our experience at a secondary care centre. J. Min Access. Surg., 9: 7-12, 2013.

13- SCHIER F., DANZER E. and BONDARTSCHUK M.: Incidence of contralateral patent processus vaginalis in children with inguinal hernia. J. Pediatr. Surg., 36 (10): 1561-1563, 2001.

14- ESPOSITO C., ESCOLINO M., FARINA A., et al.: Two decade of history of laparoscopic pediatric inguinal hernia repair. J. Laparoendosc Adv. Surg. Tech. A., 24 (9): 669670,2014

15- OSTLIE D. and PONSKY T.: Technical options of the laparoscopic pediatric inguinal hernia repair. J. Laparoendosc Adv. Surg. Tech. A., 24 (3): 194-198, 2014.

16- URE B., BAX N. and VAN DER ZEE D.: Laparoscopy in infants and children: a prospective study on the feasibility and the impact on routine surgery. J. Pediatr. Surg., 35: 1170-1173, 2000.

17- SCHAFER M., LAUPER M. and KRAHENBUHL L.: Trocar and Veress needle injuries during laparoscopy. Surg. Endosc., 15: 275-280, 2001.

18- SHALABY R., ISMAIL M., DORGHAM A., et al.: Laparoscopic hernia repair in infancy and childhood: Evaluation of 2 different techniques. J. Pediatr. Surg., 45: 2210-6, 2010.

19- SCHIER F.: Laparoscopic inguinal hernia repair-a prospective personal series of 542 children. J. Pediatr. Surg., 41: 1081-4, 2006.

20- ESPOSITO C., MONTINARO L., ALICCHIO F., et al.: Laparoscopic treatment of inguinal hernia in the first year of life. J. Laparoendosc Adv. Surg. Tech. A., 20(5): 473476, 2010

21- MARTE A., SABATINO M., BORRELLI M., et al.: Decreased recurrence rate in the laparoscopic herniorrhaphy in children: Comparison between two techniques. J. Laparoendosc Adv. Surg. Tech. A., 19: 259-262, 2009.

22- BOO Y., et al.: Laparoscopic hernia sac transection and intracorporeal ligation show very low recurrence rate in pediatric inguinal hernia. J. Laparoendosc Adv. Surg. Tech. A., 22: 720-723, 2012.
23- TABRIZIAN F., RAISOLSADAT S., HOUSHMAND B., et al.: Assessment of the necessity of sac high ligation in inguinal hernia open surgery among children. J. Pediatr. Surg., 48: 547-549, 2013.

24- T. IWANAKA, H. UCHIDA, H. KAWASHIMA, et al.: complications of laparoscopic surgery in neonates and small infants. Journal of Pediatric Surgery, Volume 39: pp. 1838-1841, 2008.

25- KALA N., ALLAL H., RAUX O., et al.: Tolerance of laparoscopy and Thoracoscopy in Neonates, Volume 116: p785-791, 2005.

26- LAU S., LEE Y. and CATY M.: Current management of hernias and hydroceles. Semin Paediatr. Surg., 16: 5057, 2007.

27- WHEELER A., MATZ S., SCHMIDT S., et al.: Laparoscopic Inguinal Hernia Repair in Children with Transperitoneal Division of the Hernia Sac and Proximal Purse String Closure of Peritoneum: Our Modified New Approach. Eur. J. Pediatr. Surg., 21: 381-385, 2011.

28- HERNÁNDEZ C., FIGUEROA L., GUTIÉRREZ R., et L.: Laparoscopic approach for inguinal hernia in children: Resection without suture. Journal of Pediatric Surgery, 47, 2093-2095, 2012.

29- IBRAHIM M.: Two Ports Laparoscopic Inguinal Hernia Repair in Children. Minimally Invasive Surgery Volume, Vol (2015): 1-5 (http://dx.doi.org/10.1155/2015/821680), 2015.

30- SHALABY R., IBRAHEM R., SHAHIN M., et al.: Laparoscopic hernia repair versus open herniotomy in children: A controlled randomized study. Minim Invasive Surg., 2012: 1-8, 2012.

31- PARELKAR S., OAK S., GUPTA R., et al.: Laparoscopic inguinal hernia repair in the pediatric age group-Experience with 437 children. J. Pediatr. Surg., 45: 789-782, 2010.

32- SHAH R., ARLIKAR J., DHENDE N.: Incise, dissect, excise and suture technique of laparoscopic repair of pediatric male inguinal hernia. J. Minim. Access. Surg., 9: 72-75, 2013.

33- TREEF W. and SCHIER F.: Characteristics of laparoscopic inguinal hernia recurrences. Pediatr. Surg. Int., 25: 14952, 2009. 


\section{إصلاح الفتق الإربى بالمنظار الجراحى المئى فى الأطفال عن طريق فصل كيس الغورئ الفتق}

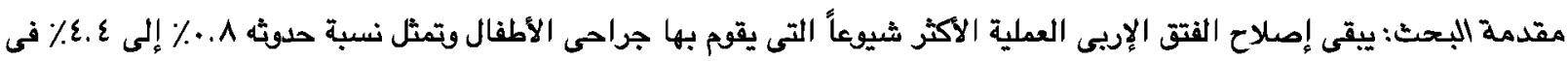

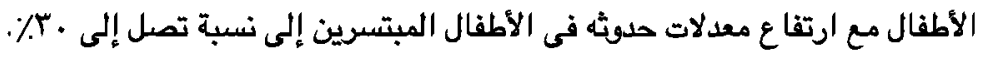
ومى ان الاصلاح التقليدى للفتق الاربى بواسطة الفتح الجراحى هو الطريقة القياسية لكن لا يخلو من المضاعفات ومنها إصابة الوعاء

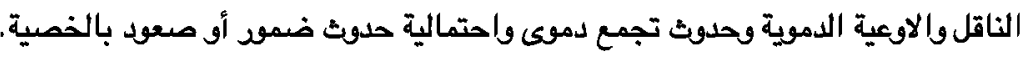

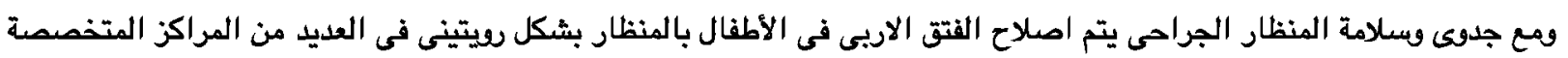

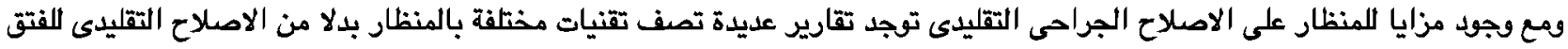

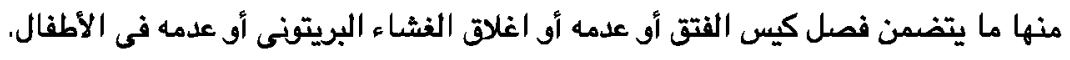

الغرض من البحث: الهدف من دراستنا تقييم اصلاح الفتق الاربى بالمنظار الجراحى فى الأطفال بواسطة فصل كيس الفتق فيما يتطلق

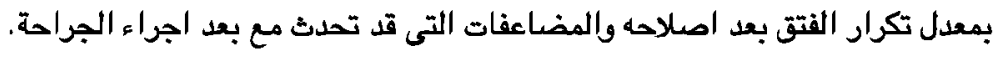

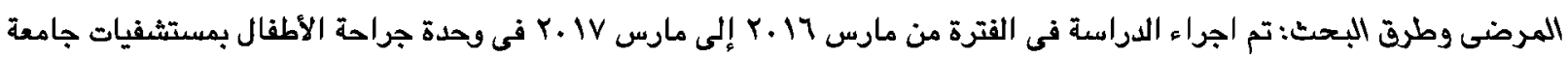

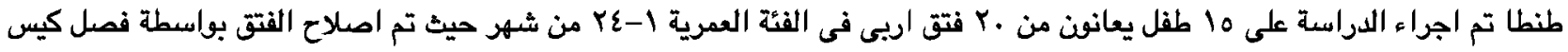
الفتق فقط.

قبل اجراء الجراحة تم عمل تقييم وفحص بدنى مع اجراء الفحوصات اللازمة والموجات فوق الصوتية لفحص الخصية المقابلة بحثاً عن فتق كامن.

النتائج: وكان متوسط العمر في هذه الدراسة 0.0 شهر وكان الفتق الاربى على ناحية واحدة فى . الالات بينما كان موجود على الناحيتين

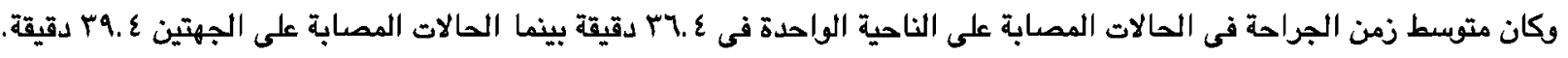

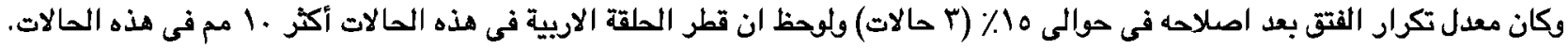

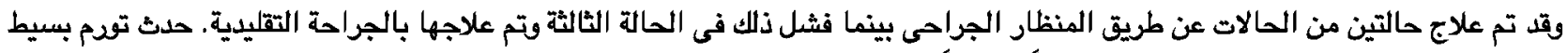

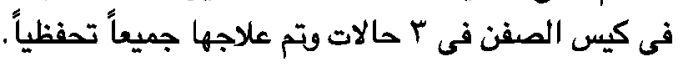

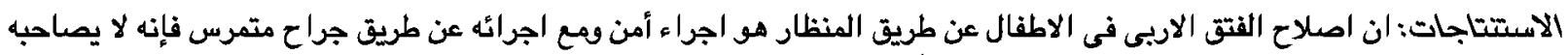

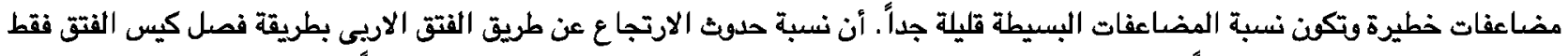

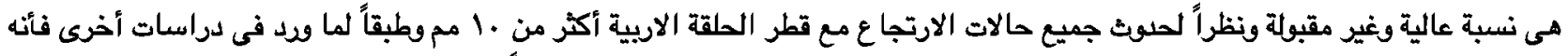

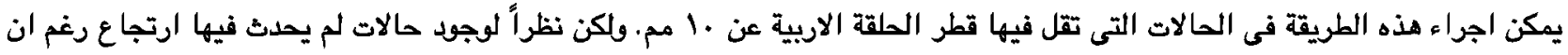

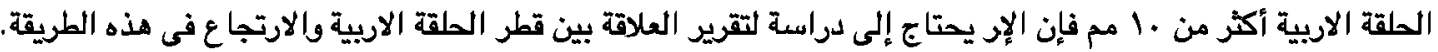

